\title{
Glycated Albumin as Marker for Early Hyperglycemia Detection in Adolescent with $\beta$ Thalassemia Major
}

\author{
Dewinda Candrarukmi ${ }^{1,2, *}$, Annang Giri Moelyo ${ }^{1,2,3}$, Muhammad Riza ${ }^{1,2,4}$ \\ ${ }^{1}$ Faculty of Medicine, Universitas Sebelas Maret, J1. Kolonel Sutarto, Surakarta 57126, Indonesia \\ ${ }^{2}$ Department of Child Health, Dr. Moewardi Regional General Hospital Hospital, Jl. Kolonel Sutarto No.132, Surakarta 57126, Indonesia \\ ${ }^{3}$ Pediatric Endocrinology Subdivision, Department of Child Health, Dr. Moewardi Regional General Hospital Hospital, Jl. Kolonel Sutarto No.132, \\ Surakarta 57126, Indonesia \\ ${ }^{4}$ Pediatric Hematooncology Subdivision, Department of Child Health, Dr. Moewardi Regional General Hospital Hospital, J1. Kolonel Sutarto No.132, \\ Surakarta 57126, Indonesia \\ *Corresponding author. E-mail: d.winda.candraru@gmail.com
}

Received date: Mar 15, 2021; Revised date: May 29, 2021; Accepted date: Jun 4, 2021

\section{Abstract}

$\mathrm{B}$

ACKGROUND: Hyperglycemia is one of the most common endocrine complications in children with $\beta$ thalassemia major. Though the current diagnostic marker either requires fasting, has low reproducibility, or it is not an accurate for thalassemia patients. Glycated albumin (GA) is a quick and easy alternative marker for hyperglycemia detection and monitoring of glycemic control. However to date, no studies have analyzed the role of GA value in detection of hyperglycemia in children with thalassemia major. This study analyzed the value of GA as an alternative screening marker for hyperglycemia detection in children with $\beta$ thalassemia major.

METHODS: A single-blind prospective diagnostic test was conducted in 9 to 18 years old children with $\beta$ thalassemia major and who were treated at the Dr. Moewardi Regional General Hospital between October 1, 2018 and December 31, 2019. In a single, fasted study visit, height, weight, fasting blood glucose (FPG), GA, oral glucose tolerance test (OGTT) were measured. The area under a receiver operating characteristic curve (AUC) was used to determine the cut-off value at which hyperglycemia prediction (OGTT $\geq 140 \mathrm{mg} / \mathrm{dL}$ ) display optimal sensitivity and specificity.

RESULTS: Among the 53 children with $\beta$ thalassemia major, $1(1.9 \%)$ had diabetes mellitus and 4 (7.5\%) had prediabetes based on their OGTT values. The median GA value in this study was $10.9 \%$ (range: $7.6-12.4 \%$ ). GA had a low $\operatorname{AUC}(0.646, p=0.287)$ for hyperglycemia detection in pediatric patients with $\beta$ thalassemia major. At a cut-off of $11.45 \%$, GA demonstrated $60 \%$ sensitivity and $60.4 \%$ specificity.

CONCLUSION: GA cannot be used as an alternative marker for hyperglycemia detection in children with $\beta$ thalassemia major.

KEYWORDS: hyperglycemia, diabetes mellitus, prediabetes, $\beta$ thalassemia major, glycated albumin

Indones Biomed J. 2021; 13(3): 281-8

\section{Introduction}

With the improvement of thalassemia management, such as the combination of blood transfusion and iron chelation therapy, the life expectancy of children with thalassemia has increased; however, the endocrine complications has also risen, and such complications can interfere with the growth and quality of life of a patient. The endocrine complications commonly found in children with $\beta$ thalassemia major include growth and puberty disorders, impaired gonadal function, impaired thyroid function, parathyroid and adrenal diseases, diabetes, and impaired bone growth.(1) 
Impaired glucose homeostasis or hyperglycemia in children with $\beta$ thalassemia major can range from mild glucose intolerance to diabetes mellitus (DM). Impaired glucose tolerance appears in the early stages of adolescence coinciding with puberty. DM is a rare condition that appears in the first decade of life, and its incidence rate increases with age.(2)

The exact mechanism of glucose metabolism disorders in patients with $\beta$ thalassemia major remains controversial. The diagnoses criteria for DM and prediabetes are based on the American Diabetes Association (ADA) criteria.(3) The most accurate method for diagnose glucose metabolism disorders in patient with $\beta$ thalassemia major is still controverted. Some studies suggested that oral glucose tolerance test (OGTT) should be performed in all patients with $\beta$ thalassemia major after they turn 10 years old or even earlier if needed.(4) Compared with the fasting blood glucose (FBG) examination, which requires fasting, OGTT requires repeated blood drawing apart from fasting, and it demonstrates low reproducibility. While HbA1c is a DM diagnostic test that is easy to perform, it is not an accurate DM diagnostic test for thalassemia patients.

Glycated albumin (GA) is a type of albumin that undergoes a non-enzymatic reaction with reduced sugar or its degradation products. In vivo studies showed that the proportion of GA in healthy individuals is $1-10 \%$, whereas it is higher by 2-3 times in DM patients.(5) GA values are associated with heart disease, stroke ischemia, heart failure, and death.(6) Moreover, other studies showed that the effect of GA on microangiopathy is correlated with kidney disorders in people with diabetes.(7)

GA is a fast and easy alternative marker for the diagnosis and evaluation of glycemic control in patients with DM. However, to date, no studies have analyzed the role of GA value in the detection of prediabetes and DM in children with thalassemia major. This study analyzed the value of GA as an alternative screening marker for hyperglycemia detection in children with $\beta$ thalassemia major, with oral glucose tolerance test (OGTT) as the gold standard.

\section{Methods}

This study employed a prospective diagnostic test study design with sample included 9 to 18 years old children with $\beta$ thalassemia major and who were treated in the pediatric ward of Dr. Moewardi Regional General Hospital, Surakarta between October 1, 2018 and December 31, 2019.

\section{Sample Recruitment}

The patients were selected through consecutive sampling until the required number of samples was met. The patients with $\beta$ thalassemia major were identified based on $\mathrm{Hb}$ electrophoresis examination result in patient's medical record. The patients received routine packet red cell transfusions in the same hospital. Patients with other systemic diseases (e.g., liver disorders (hepatic cirrhosis), chronic renal failure, hypothyroidism, and hyperthyroidism) or those taking drugs that affect blood glucose values (e.g., insulin, oral diabetes drugs, and corticosteroids) were excluded from this study. This research was approved by the Health Research Ethics Committee of the Dr. Moewardi Regional General Hospital / Faculty of Medicine, Universitas Sebelas Maret (No: 690/IX/HREC/2018) and informed consent was obtained from each included patient.

\section{OGTT and GA Level Measurement}

Hyperglycemia conditions, including prediabetes and DM, were diagnosed using the ADA criteria.(3) In this study, the OGTT value was used as the gold standard for diagnosis. At the second-hour of OGTT, the plasma glucose levels are $140-199 \mathrm{mg} / \mathrm{dL}$ in prediabetes whereas those in DM are $>200 \mathrm{mg} / \mathrm{dL}$.

In a single, fasted study visit, height $(\mathrm{cm})$, weight $(\mathrm{kg})$, FPG, GA, OGTT $(1.75 \mathrm{~g} / \mathrm{kg}$ BW of oral glucose, maximum $75 \mathrm{~g}$ ) with a 2-hour plasma glucose concentration were attained. OGTT was measured from a venous sample (3 $\mathrm{mL}$ ) placed in a tube containing the anticoagulant potassium oxalate and $\mathrm{NaF}$. The measurement was performed using the hexokinase method on a C-501 analyzer. The reagent used was Roche, and a GLU Reagent Kit, which has a detection range of $0.6-600 \mathrm{mg} / \mathrm{dL}$, was used. GA was measured from venous blood sample $(6 \mathrm{~mL})$ placed in a clot activator tube. The examination was carried out using the colorimetric enzymatic method on an Architech analyzer, with GA-L as reagent. The reference values used ranged from $11 \%$ to $16 \%$.

This work is a single-blind diagnostic study, that was, the staff who took the blood samples and the laboratory staff did not know whether the blood sample being tested for GA levels belongs to a certain patient with normoglycemia, prediabetes, or DM based on OGTT.

\section{Statistical Analysis}

The sample size for a diagnostic study that has an area under the curve (AUC) output was determined.(8) In this study, the minimum number of samples was $n=50.63(\sim 51$ samples). The distribution of the baseline data for this 
study was assessed using the Kolmogorov-Smirnov test, and statistical significance was set at $p>0.05$. Continuous variables are presented as mean \pm standard deviation (SD) or as median \pm interquartile range. The characteristics of the patients with normoglycemia, prediabetes, and DM were analyzed using the Chi square test for categorical data and the Kruskal-Wallis test for numeric data. GA levels were analyzed by independent T-test and Pearson test. Statistical analysis of the diagnostic test results, graphs, and receiver operating characteristic (ROC) curves was performed using SPSS version 22 (IBM Corporation, Armonk, NY, USA). The cut-off value for GA levels of a population of Indonesian adolescents with thalassemia was obtained from the area under curve (AUC) by determining the best cut-off in terms of sensitivity and specificity of the GA in detecting hyperglycemia, with OGTT as the reference. Statistical significance was set at $p<0.05$. Samples that do not have OGTT and GA data were excluded from this study.

\section{Results}

A total of 53 pediatric patients with $\beta$ thalassemia major met the inclusion criteria (Figure 1). The characteristics of these patients were shown in Table 1. Continuous variables are presented as mean $\pm \mathrm{SD}$ if they are normally distributed and as median (minimum-maximum) if they are not normally distributed. Categorical variables are presented as frequency distribution (\%).

Most of the patients had an adequate nutritional status $(54.7 \%)$, but they were stunted (56.6\%) (Table 1).
In the sample of this study, there were many patients who had pretranfused hemoglobin $(\mathrm{Hb})$ less than target $9 \mathrm{~g} / \mathrm{dL}$ (60.4\%). Based on the history anamnesis, no patient had a family history of DM, and none had complaints involving polyuria, polydipsia, or polyphagia.

In this study, the patient with DM was a 13 years old female who had regular transfusions for 10 years, had adequate nutritional status with a height within the normal range, and had a ferritin level of $5045.6 \mathrm{ng} /$ $\mathrm{mL}$. Meanwhile, the thalassemia major patients with normoglycemia, prediabetes, and DM showed no significant difference $(p<0.05)$ in terms of age $(p=0.883)$, nutritional status $(p=0.311)$, incidence of short stature $(p=0.488)$, age of diagnosis $(p=0.369)$, duration of blood transfusion ( $p=0.141$ ), type of iron chelation (0.969), ferritin level $(p=0.766)$, and $\mathrm{Hb}$ level $(p=0.148)$ (Table 2). The mean ferritin $(p=0.766)$ and FBG $(p=0.242)$ levels were higher in patients with DM than in patients with prediabetes or normoglycemia, but the difference was not statistically significant.

The median GA value was 10.9\% (range: 7.6-12.4\%). No significant difference in the GA value was observed in terms of gender $(p=0.771)$ and nutritional status $(p=0.192)$ (Table 3). A weak positive correlation was observed between GA and age ( $\mathrm{r}=0.045, p=0.749)$, but this correlation was not statistically significant. Similarly, no significant correlation was observed between ferritin and FBG levels $(p=0.749)$, OGTT ( $p=0.497)$, or GA $(p=0.060)$ (Table 4$)$.

ROC curve analysis was used to determine the optimum cut-off value of GA levels for the detection of hyperglycemia (prediabetes and DM) in patients with $\beta$

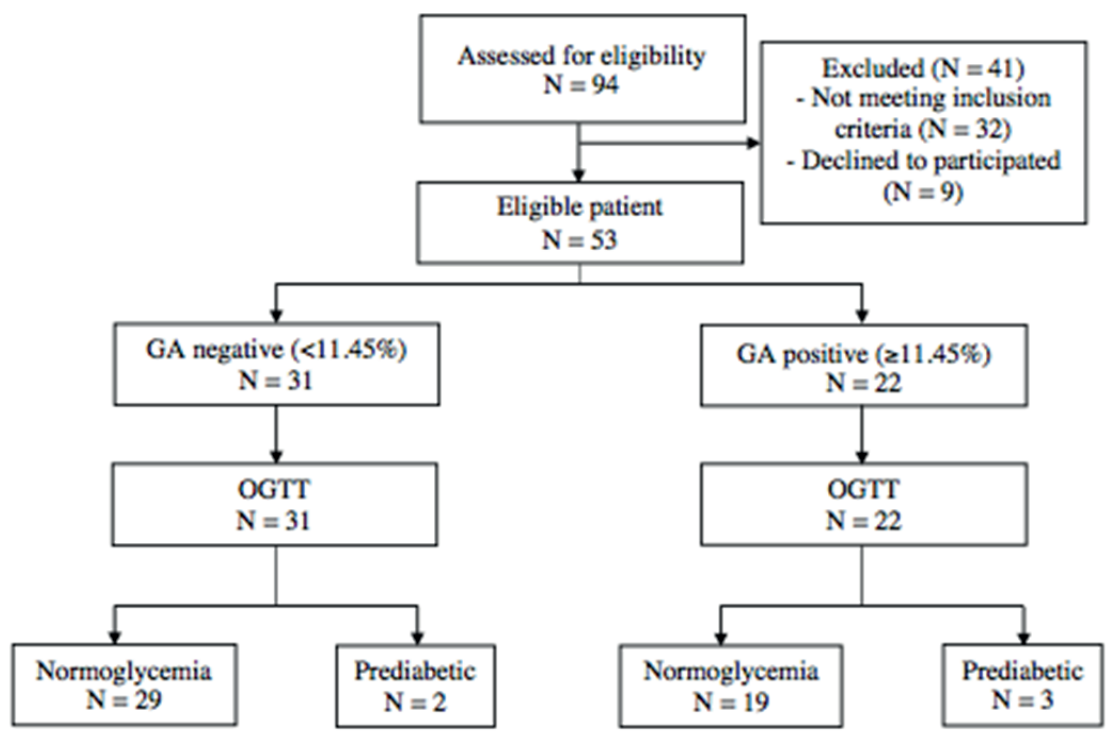

Figure 1. CONSORT flow diagram of sample enrollment. 
Table 1. Characteristics of the study sample.

\begin{tabular}{|c|c|}
\hline Variable & Value \\
\hline \multicolumn{2}{|l|}{ Gender (n, \%) } \\
\hline Male & $23(43.4 \%)$ \\
\hline Female & $30(56.6 \%)$ \\
\hline Age (median, year) & $12(9-17)$ \\
\hline \multicolumn{2}{|l|}{ Nutritional status (n, \%) } \\
\hline Severe protein-energy malnutrition & $0(0 \%)$ \\
\hline Malnutrition & $23(43.4 \%)$ \\
\hline Normoweight & $29(54.7 \%)$ \\
\hline Overweight & $1(1.9 \%)$ \\
\hline Obesity & $0(0 \%)$ \\
\hline \multicolumn{2}{|l|}{ Height (n, \%) } \\
\hline Stunted & $30(56.6 \%)$ \\
\hline Normoheight & $23(43.4 \%)$ \\
\hline Age of thalasemia diagnosis (mean, year) & $5.63 \pm 3.65$ \\
\hline Duration of transfusion (mean, year) (n, \%) & $6.63 \pm 3.00$ \\
\hline$<1$ year & $1(1.9 \%)$ \\
\hline $1-5$ year & $20(37.7 \%)$ \\
\hline$>5$ year & $32(60.4 \%)$ \\
\hline \multicolumn{2}{|l|}{ Iron chelation } \\
\hline Deferiprone & $10(18.9 \%)$ \\
\hline Deferaxirox & $41(77.4 \%)$ \\
\hline Without chelation & $2(3.8 \%)$ \\
\hline Ferritin (mean, ng/mL) & $3831.15 \pm 2225.78$ \\
\hline Pretransfusion $\mathrm{Hb}$ level (median, g/dL) (n, \%) & $8.65 \pm 6.59$ \\
\hline$<7 \mathrm{~g} / \mathrm{dL}$ & $2(3.8 \%)$ \\
\hline $7-9 \mathrm{~g} / \mathrm{dL}$ & $30(56.6 \%)$ \\
\hline$>9 \mathrm{~g} / \mathrm{dL}$ & $21(39.6 \%)$ \\
\hline FBG (mean, mg/dL) & $82.8 \pm 6.59$ \\
\hline GA (median, \%) & $10.90(7.6-12.4)$ \\
\hline \multicolumn{2}{|l|}{ Glucose metabolism disorder } \\
\hline Normal & $48(90.6 \%)$ \\
\hline Prediabetes & $4(7.5 \%)$ \\
\hline DM & $1(1.9 \%)$ \\
\hline
\end{tabular}

thalassemia major. In the analysis based on the ROC curve, AUC was $0.646(p=0.287, p>0.05)$ when the cut-off GA value was $11.45 \%$. At this cut-off value, GA demonstrated $60 \%$ sensitivity, $60.4 \%$ specificity, $13.6 \%$ positive predictive value, and $93.5 \%$ negative predictive value for hyperglycemia detection in patients with $\beta$ thalassemia major.

\section{Discussion}

$\mathrm{DM}$ and prediabetes in children with $\beta$ thalassemia mayor are diagnosed by using the ADA criteria.(3) Based on the OGTT levels, the prevalence of DM was $1.9 \%$ and that of prediabetes was $7.5 \%$ in the 53 pediatric patients with $\beta$ thalassemia major treated at the Dr. Moewardi Regional General Hospital. These prevalence rates are consistent with previous findings showing that the prevalence of DM in $\beta$ thalassemia major varied from $2 \%$ to $9.4 \%(2,9-14)$ and that the prevalence of impaired glucose tolerance ranged from $4.4 \%$ to $30 \%$ (9-12). In this study, all FBG levels were within the normal limits. However, another study reported that the frequency of fasting blood sugar disorders in patients with $\beta$ thallasemia major aged 10-20 years was $14.8 \%$.(14)

Study in Chinese children reported that ages older than 10 years and ferritin levels higher than $2500 \mathrm{np} / \mathrm{mL}$ were associated with abnormalities in glucose metabolism in patients with $\beta$ thalassemia major.(11) However, in this study, no significant difference $(p<0.05)$ was observed among the $\beta$ thalassemia major patients with normoglycemia, prediabetes, and DM in terms of age, nutritional status, incidence of short stature, age of diagnosis, duration of blood transfusion, type of chelating iron, ferritin level or pretransfusion $\mathrm{Hb}$ levels.

$\mathrm{DM}$ in patients with $\beta$ thalassemia major is hypothesized to be caused by iron accumulation in tissues that regulate glucose metabolism, such as liver and pancreas. The buildup of iron in the liver causes insulin resistance in the liver. Moreover, the buildup of iron in muscles can reduce glucose uptake by myocytes. In the pancreas, the accumulation of iron exerts oxidative stress to the pancreatic cells, leading to apoptosis, decrease in pancreatic volume, activation of the immune system against pancreatic cells, fat transformation, and pancreatic dysfunction that results in insulin deficiency and contributes to insulin-dependent diabetes.(15-20)

Another study stated that excessive iron accumulation in the pancreas as revealed by T2-MRI examination was associated with an increase in fasting insulin levels.(21) In the liver, increased iron accumulation was revealed by $\mathrm{T} 2 *$-MRI scans and was accompanied by increased insulin resistance marked by an increase in the value of homeostatic model assessment for insulin resistance (HOMA-IR). Moreover, insulin resistance accompanied by hyperinsulinism conditions in order to maintain blood glucose homeostasis in patients with $\beta$ thalassemia major may occur even though the glucose tolerance is normal.(4) In the event the glucose tolerance is impaired, a patient may display insulin resistance accompanied by decreased insulin secretion. Given that impaired glucose tolerance and insulin resistance occur before the onset of DM, early detection of prediabetes and DM is important.

In this study, the patients with DM had FBG levels that fall within the normal range (GDP: $96 \mathrm{mg} / \mathrm{dL}$ ); however, 
Table 2. Characteristics of the patients with prediabetes and DM.

\begin{tabular}{|c|c|c|c|c|}
\hline Variable & $\begin{array}{c}\text { DM } \\
(n=1)\end{array}$ & $\begin{array}{c}\text { Prediabetes } \\
\qquad(n=4)\end{array}$ & $\begin{array}{l}\text { Normal } \\
(n=48)\end{array}$ & $p$-value \\
\hline Age $(\text { year })^{\dagger}$ & $13.00 \pm 0.00$ & $12.00 \pm 3.74$ & $12.35 \pm 2.70$ & 0.883 \\
\hline Gender ${ }^{*}$ & & & & 0.657 \\
\hline Male & $0(0.0 \%)$ & $2(50.0 \%)$ & $21(43.8 \%)$ & \\
\hline Female & $1(100.0 \%)$ & $2(50.0 \%)$ & $27(56.3 \%)$ & \\
\hline Nutritional status $^{\dagger}$ & & & & 0.311 \\
\hline Malnutrition & $0(0.0 \%)$ & $3(75.0 \%)$ & $20(41.7 \%)$ & \\
\hline Normoweight & $1(100.0 \%)$ & $1(25.0 \%)$ & $27(56.3 \%)$ & \\
\hline Overweight & $0(0.0 \%)$ & $0(0.0 \%)$ & $1(2.1 \%)$ & \\
\hline Height ${ }^{*}$ & & & & 0.488 \\
\hline Stunted & $0(0.0 \%)$ & $2(50.0 \%)$ & $28(58.3 \%)$ & \\
\hline Normoheight & $1(100.0 \%)$ & $2(50.0 \%)$ & $20(41.7 \%)$ & \\
\hline Age of thalassemia diagnosis (year) ${ }^{\dagger}$ & $2.50 \pm 0.00$ & $8.00 \pm 6.06$ & $5.50 \pm 3.41$ & 0.369 \\
\hline Duration of transfusion ${ }^{\dagger}$ & & & & 0.141 \\
\hline$<1$ year & $0(0.0 \%)$ & $1(25.0 \%)$ & $0(0.0 \%)$ & \\
\hline $1-5$ years & $0(0.0 \%)$ & $2(50.0 \%)$ & $18(37.5 \%)$ & \\
\hline$>5$ years & $1(100.0 \%)$ & $1(25.0 \%)$ & $30(62.5 \%)$ & \\
\hline Iron chelation ${ }^{*}$ & & & & 0.969 \\
\hline Exjade & $0(0.0 \%)$ & $1(25.0 \%)$ & $9(18.8 \%)$ & \\
\hline Feriprox & $1(100.0 \%)$ & $3(75.0 \%)$ & $37(77.1 \%)$ & \\
\hline Without any & $0(0.0 \%)$ & $0(0.0 \%)$ & $2(4.2 \%)$ & \\
\hline Ferritin $(\mathrm{np} / \mathrm{mL})^{\dagger}$ & $5046.50 \pm 0.00$ & $4127.25 \pm 3106.84$ & $3781.15 \pm 2196.27$ & 0.766 \\
\hline 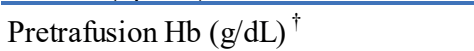 & & & & 0.148 \\
\hline$<7$ & $0(0.0 \%)$ & $0(0.0 \%)$ & $2(4.2 \%)$ & \\
\hline $7-9$ & $0(0.0 \%)$ & $1(25.0 \%)$ & $29(60.4 \%)$ & \\
\hline$>9$ & $1(100.0 \%)$ & $3(75.0 \%)$ & $17(35.4 \%)$ & \\
\hline FBG (g/dL) & $96.00 \pm 0.00$ & $83.00 \pm 4.08$ & $82.38 \pm 6.57$ & 0.242 \\
\hline
\end{tabular}

The numerical data obtained are presented as mean \pm SD or median (min-max), whereas the categorical data are presented as F (\%); ${ }^{\dagger}$ Kruskal-Wallis test (numerical data do not meet the normality requirements or ordinal categorical data); ${ }^{\ddagger}$ Chi sqaure test (nominal categorical data).

their OGTT levels were high $(246 \mathrm{mg} / \mathrm{dL})$. Study in Thai adult at the age of 35-65 years old, the use of FBG missed

Table 3. The relationship of GA with gender and nutritional status.

\begin{tabular}{lcc}
\hline \multicolumn{1}{c}{ Variabel } & Mean \pm SD & p-value \\
\hline Gender $^{\dagger}$ & & 0.771 \\
Male & $10.76 \pm 1.12$ & \\
Female & $10.87 \pm 1.14$ & \\
\hline Nutritional status $^{\ddagger}$ & & \\
Malnutrition & $10.52 \pm 1.26$ & 0.192 \\
Normoweight & $11.09 \pm 0.95$ & \\
Overweight & $9.90 \pm 0.00$ & \\
\hline
\end{tabular}

The numerical data obtained are presented as mean $\pm \mathrm{SD}$ or median (min-max), whereas the categorical data are presented as F (\%); ${ }^{\dagger}$ Chi square test (numeric data); ${ }^{*}$ Kruskal-Wallis test (numerical data do not meet the normality requirements or ordinal categorical data). the diagnosis of prediabetes and diabetes at a rate of $46.3 \%$ and $54.7 \%$, respectively.(22) Diagnosis of DM at the age of 35-55 years based on FBG, HbA1c, and OGTT was reported to be $56.7 \%, 53.6 \%$, and $84.5 \%$, respectively.(23) Impaired FBG occurs due to insulin resistance in the liver and impaired initial insulin response, whereas impaired OGTT occurs due to insulin resistance in muscles and liver and dysfunction of pancreatic cells.(24) In this study, the patient with DM had an impaired OGTT but had FBG levels that fall within the normal limits; thus, hyperglycemia was probably due to insulin resistance in the muscles and liver and due to the impaired function of pancreatic cells.

GA levels can be used to monitor glycemia in conditions that result in changes in Hb levels, in the second/ third trimester of pregnancy, in patients with terminal chronic renal failure, and in neonates, as well as in monitoring short-term changes in glycemia.(25) A multicenter study 
Table 4. Correlation of ferritin with FBG, OGTT and GA.

\begin{tabular}{lc}
\multicolumn{1}{c}{ Variabel } & Ferritin \\
\hline $\mathrm{FBG}^{\dagger}$ & \\
$\mathrm{r}$ (correlation coefficient) & 0.045 \\
$p$-value & 0.749 \\
\hline $\mathrm{OGTT}^{\ddagger}$ & \\
$\mathrm{r}$ (correlation coefficient) & -0.095 \\
$p$-value & 0.497 \\
\hline $\mathrm{GA}^{\ddagger}$ & \\
$\mathrm{r}$ (correlation coefficient $)$ & -0.26 \\
$p$-value & 0.06 \\
\hline
\end{tabular}

${ }^{\dagger}$ Pearson Test; ${ }^{\star}$ Spearman rank test.

at Italia stated that in patients with $\beta$ thalassemia major, GA has a stronger correlation with FBG (GA ${ }^{2}=0.693$, HbA1c $\left.r^{2}=0.370\right)$ compared with HbA1c.(7) In this study, the $\mathrm{HbA} 1 \mathrm{c}$ level was not measured and thus the correlation between GA and HbA1c could not be assessed.

Many study demonstrated the value of GA for diagnosis of DM in adult patient. Most of them indicated a GA level with optimal AUC, sensitivity and specificity.(26-28) Data on the use of GA as an alternative marker for hyperglycemia detection in children remain limited. To date, no studies have determined the cut-off value for GA for hyperglycemia detection in pediatric patients with $\beta$ thalassemia major. This study found that GA had a median of $10.9 \%$ (range: 7.6-12.4\%). As reported by another study from Indonesia, the GA levels in $\beta$ thalassemia major patients aged 11-28 years old had a mean of $10.3 \%$ (range: $8.3-12 \%$ ); however, blood glucose levels were not measured.(29)

The diagnostic value of GA for the detection of hyperglycemia (diabetes and prediabetes) in children with $\beta$ thalassemia major was analyzed in this study. The GA levels with a cut-off of $11.45 \%$ could detect hyperglycemia in pediatric patients with $\beta$ thalassemia major, but they have low AUC (0.646, $p=0.287), 60 \%$ sensitivity, $60.4 \%$ specificity, $13.6 \%$ positive predictive value, and $93.5 \%$ negative predictive value. Thus, GA does not perform well in terms of detection of hyperglycemia conditions in pediatric patients with $\beta$ thalassemia major.

The results of this study are consistent with the findings of previous study on obese adolescents, wherein a GA level with a cut-off of $12 \%$ (AUC: 0.9209 ) could detect a OGTT value of more than $200 \mathrm{mg} / \mathrm{dL}$; moreover, a GA level with a cut-off of $14 \%$ (AUC: 0.9843 ) could detect $\mathrm{HbA1C}$ at a rate of $>6.5 \%$ in obese children, but with a low GAAUC marker (0.5394) for prediabetes detection in obese children.(30) Another study found a GA value of $>14.8 \%$
(64.9\% sensitivity, $65.5 \%$ specificity, and 0.703 AUC) for the diagnosis of DM in patients aged $>18$ years. (31)

The lower cut-off value obtained in this study is possibly due to the small study population. In addition, differences in age, ethnicity, and other types of major undelying diseases in previous studies are presumed to have contributed to the observed difference of the results obtained. Previous study stated that the normal range for GA increases with age, that is, from infant to adult (32); thus, age range must be considered when interpreting the results obtained. In this study, no differences in GA results was observed in terms of gender and nutritional status, and no correlation was found between GA and age $(\mathrm{r}=0.045$, $p=0.749$ ). The disparity between the present results and the previous findings is possibly due to the narrow age range in the study sample. This study has several limitations. Specifically, there is no follow up examination for OGTT and GA value for each sample over a period of time, and the ferritin value were obtained from the most recent data for the last 3 months in the patient records.

\section{Conclusion}

On the basis of the results, it can be concluded that GA value cannot be used as a screening tool for hyperglycemia detection in children with $\beta$ thalassemia major. Thus, it is necessary to conduct studies with a larger sample with older age range or to find other alternative markers for the detection of hyperglycemia in children with $\beta$ thalassemia

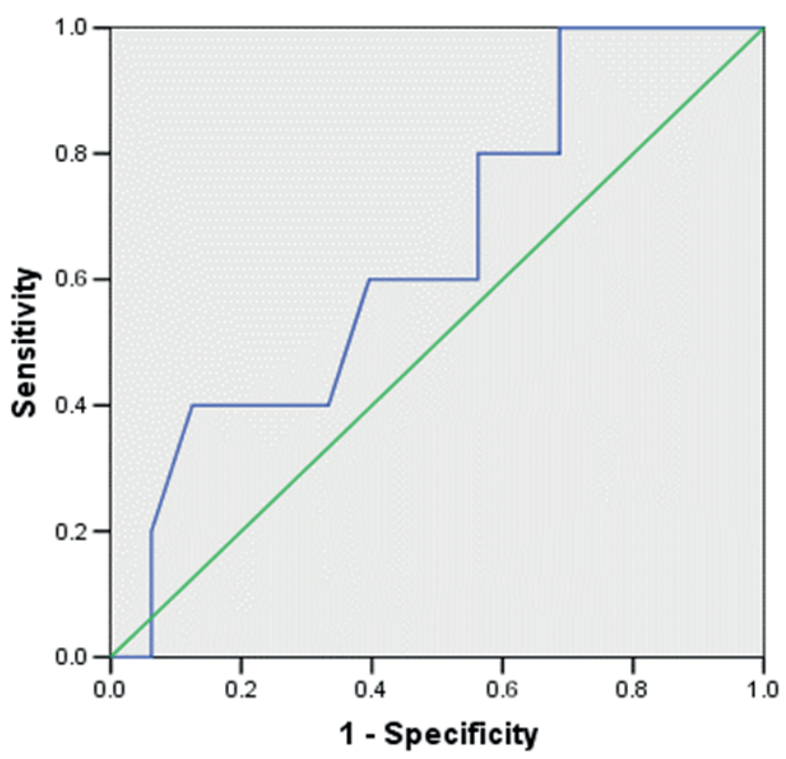

Figure 2. ROC curve of GA for hypreglicemia (AUC: 0.646, $p>0.005)$. 
major. In pediatric patients with $\beta$ thalassemia major, OGTT and FBG levels must be evaluated for early detection of and for the prevention of morbidity and mortality due to DM.

\section{Acknowledgements}

This study has been presented as ePoster at 46th Annual Conference of the International Society for Pediatric and Adolescent Diabetes (ISPAD). For measurement of OGTT and GA value, this study used resources of Prodia Clinical Laboratory.

\section{Authors Contribution}

DC designed the study, researched data, and wrote the manuscript. AGM designed the study, reviewed and edited the manuscript. MR contributed to discussion, reviewed and edited the manuscript.

\section{References}

1. De P, Mistry R, Wright C, Pachan S, Burbridge W, Gangopadhayay K et al. A review of endocrine disorder in thalassemia. Open J Endocr Metab Dis. 2014; 4: 25-34.

2. Al-akhras A, Badr M, El-safy U, Kohne E, Hassan, Abdelrahman H, et al. Impact of genotype on endocrine complication in $\beta$-thalassemia patients. Biomed Rep. 2016; 4: 728-36.

3. Pulungan A. Increasing incidence of DM type 1 in Indonesia. Int $\mathbf{J}$ Pediatr Endocrinol. 2013; (Suppl 1): O12. doi: 10.1186/1687-98562013-S1-O12.

4. Sactis VD, Skordis N. Solirhan AT. Chapter 8: Endocrine disease. In: Cappellini MD, Cohen A, Porter J, editors. Guidelines for the Management of Transfusion Dependent Thalassaemia (TDT). 3rd ed. Strovolos: Thalassemia International Federation; 2014. p.151-4.

5. Araki T, Ishikawa Y, Okazaki H. Japanese Red Cross GA Research Group: introduction of glycated albumin measurement for all blood donors and the prevalence of a high glycated albumin level in Japan. J Diabetes Investig. 2012; 3: 492-7.

6. Selvin E, Rawlings AM, Lutsey P, Maruthur N, Pankow JS, Steffes $\mathrm{M}$, et al. Fructosamine and glycated albumin and the risk of cardiovascular outcomes and death. Circulation. 2015; 132: 269-77.

7. Paroni R, Ceriotti F, Galanello R, Leoni BG, Panico A, Scurati E, et al. Performance characteristics and clinical utility of an enzymatic method for the measurement of glycated albumin. Clin Biochem. 2007; 40: 1398-405.

8. Soliman AT, Yasin M, El-awwa A, Sactis VD. Detection of glycemic abnormalities in adolescent with beta thalassemia using continuous glucose monitoring and oral glucose tolerance in adolescents and young adult with $\beta$-thalassemia major: pilot study. Indian $\mathrm{J}$ Endocrinol Metab. 2013; 17: 490-5.

9. Metwalley KA, El-saeid ARAH. Glucose homeostasis in egyptian children and adolescent with $\beta$-thalassemia mayor: relationship to oxidative stress. Indian J Endocrinol Metab. 2014; 18: 333-9.

10. Altincik A, Akin M. Prevalence of endocrinopathies in Turkish children with $\beta$-thalassemia mayor: a single center study. J Pediatric Hematol Oncol. 2016; 38: 389-93.

11. Liang Y, Bajoria R, Jiang Y, Su H, Pan H, Xia N, et al. Prevalence of diabetes mellitus in Chinese children with thalassemia major. Trop Med Int Health. 2017; 22: 716-24.

12. Toumba M, Sergis S, Kanaris C, Skordis N. Endocrine complication in patients with thalassemia major. Pediatric Endocrinol Rev. 2007; 5: $642-8$.

13. Sharma S, Dutt N, Sidhu M, Digra S, Meenia R. Prevalence of hypothyroidism, diabetes mellitus and delayed puberty in patient of thalassemia major in a tertiary care center of Jammu province, Jammu kashir, India. Int J Adv Med. 2017; 4: 673-7.

14. Wirawan R, Setiawan S, Kusnandar S, Munthe BG. Diabetes mellitus in $\beta$-thalassemia major patients. Med J Indones. 2003; 12: 87-93.

15. Noetzli LJ, Mittelman SD, Watanabe RM. Pancreatic iron and glucose dysregulation in thalassemia major. Am J Hematol. 2012; 87: 15560 .

16. De Sanctis V, Soliman A, Yassin M. Iron overload and glucose metabolism in subjects with $\beta$-thalassaemia major: An Overview. Curr Diabetes Rev. 2013; 9: 332-41.

17. Angelopoulos NG, Zervas A, Livadas S. Reduced insulin secretion in normoglycaemic patients with beta-thalassaemia major. Diabet Med. 2006; 23: 1327-31.

18. Meyer C, Pimenta W, Woerle HJ. Different mechanisms for impaired fasting glucose and impaired postprandial glucose tolerance in humans. Diabetes Care. 2006; 29: 1909-14.

19. Sanctis VD, Soliman AT, Elsedfy H, Alessia P, Kattamis C, Kholy $\mathrm{ME}$, et al. Diabetes and glucose metabolism in thalassemia major: An Update. Expert Rev Hematol. 2016; 9: 401-8.

20. Monge L, Pinach S, Caramellino L, Bertero MT, Dall'omo A, Carta Q. The possible role of autoimmunity in the pathogenesis of diabetes in B-thalassemia major. Diabetes Metab. 2001; 27: 149-54.

21. Bas M, Gumruk F, Gonc N, Cetin M, Tuncer M, Hazurolan T, et al Biochemical marker of glucose metabolism may be used to estimate the degree and progression of iron overload in the liver and pancreas of patient with $\beta$-thalassemia major. Ann Hematol. 2015; 94:1099104.

22. Aekplakorn W, Tantayotai V, Numsangkul S, Sripho W, Tatsto $\mathrm{N}$, Burapasiriwat $\mathrm{T}$, et al. Detecting prediabetes dan diabetes aggrement between fasting plasma glucose and oral glucose tolerance test in Thai adults. Hindawi. 2015; 2015: 396505. doi: $10.1155 / 2015 / 396505$.

23. Kim DL, Kim SD, Song KH. Is an oral glucose tolerance test still valid for diagnosing diabetes mellitus?. Diabetes Metab J. 2016; 40: 118-28.

24. Abdul-Ghani M, DeFronzo RA, Jayyousi A. Prediabetes and risk of diabetes and associated complications: impaired fasting glucose versus impaired glucose tolerance: does it matter? Curr Opin Clin Nutr Metab Care. 2016; 19: 394-9.

25. Koga M. Glycated albumin, clinical usefulness. Clin Chim Acta. 2014; 433: 96-104

26. Wu WC, Ma WY, Wei JN, Yu TY, Lin MS, Shih SR, et al. Serum glycated albumin to guide the diagnosis of diabetes mellitus. Plos One. 2016; 11: e0146780. doi: 10.1371/journal. pone. 0146780 .

27. Furusyo N, Koga T, Ai M, Otokozawa S, Kohzuma T, Ikezaki H, et al. Utility of glycated albumin for the diagnosis of diabetes mellitus in a Japanese population study: results from the Kyushu and Okinawa Population Study (KOPS). Diabetologia. 2011; 54: 3028-36.

28. Bellia C, Zaninotto M, Cosma C, Agnello L, Bivona G, Marinova M. 
Clinical usefulness of glycated albumin in the diagnosis of diabetes: result from an Italian study. Clin Biochem. 2018; 54: 68-72.

29. Devi TT, Dalimoenthe NZ, Tristina N, Lismayanti L. Kadar glycated albumin pada penderita transfusion dependent thalassemia di RSUP dr. Hasan Sadikin Bandung. J Indon Med Assoc. 2017; 67: 544-9.

30. Chan CL, Pyle L, Kelsey M, Newnes L, Zeitler PS, Nadeau KJ. Screening for type 2 diabetes and prediabetes in obese youth: evaluating alternate markers of glycemia- 1,5-anhydroglucitol, fructosamine and glycated albumin. Pediatr Diabetes. 2016; 17: 206-11.

31. Chume FC, Kieling MH, Camargo JL. Glycated albumin as diagnostic tool in diabetes: an alternative or additional test?. Plos one. 2019; 14: e0227065. doi: 10.1371/journal.pone.0227065.

32. Suzuki S, Koga M, Noriyasu N, Furuya A, Matsuo K, Tanahashi Y, et al. Age-adjusted glycated albumin: a more robust parameter to establish glycaemic control in neonatal diabetes mellitus. Ann Clin Biochem. 2014; 51: 602-5. 